Article

\title{
Analysis of Fallow Farming Decision-Making Behavior of Farmers Based on Hawk-Dove Game Theory: The Case of Guizhou Province
}

\author{
Hualin Xie * and Qing Wu \\ Institute of Ecological Civilization, Jiangxi University of Finance and Economics, Nanchang 330013, China \\ * Correspondence: xiehualin@jxufe.edu.cn
}

Received: 16 May 2019; Accepted: 9 July 2019; Published: 12 July 2019

\begin{abstract}
Implementing a land fallow policy is of great significance for ensuring China's food security and promoting the improvement of the ecological environment. The implementation of a fallow project involves different stakeholders. Farmers are the main participants in the fallow project. The decision of farmers to practice fallow is the key factor for the successful development of the fallow project. Therefore, this study theoretically reveals the decision-making mechanism of farmers' participation in cultivated land fallow by utilizing the hawk-dove evolutionary game theory among farmers and explains some challenges in the implementation of fallow in Guizhou Province. We drew the following conclusions: (1) The behavior of farmers will be affected by other farmers in the same situation, and the effects of mutual incentives and imitations between the groups of farmers are affected by their interests; (2) in the fallow project, the rate of choosing either fallow or unfallow depends on the ratio of fallow income to planting income. If the income of participating in fallow is higher, the demonstration effect of farmers participating in fallow is stronger, and the strategy of continued cultivation is adopted. The fewer unfallow farmers there are, the more consolidated the results of fallow will be; and (3) the government should protect the income of farmers after fallow as much as possible, implement flexible subsidy policies, and formulate corresponding policies to successfully consolidate the fallow results.
\end{abstract}

Keywords: cultivated land fallow; farmer group; hawk-dove game theory; compensation; decision-making behavior

\section{Introduction}

With its rapid economic development and urbanization, China's traditional extensive use of cultivated land can no longer meet the current requirements of sustainable development. Despite a 13-year continuous increase in food production, Chinese farmers' incomes are still lower than other industries. On the other hand, continuous degradation of large-scale cultivation poses a serious threat to food security, environment, and economic and social development. In some areas, erosion, acidification, compaction, and desertification of land have become serious agricultural and environmental problems. The deterioration of cultivated land and the ecological environment has further threatened China's food security [1,2]. To solve the negative externalities caused by unreasonable arable land use, the Chinese government, for the first time, proposed to implement the arable Land Fallow Project (LFP) at the Fifth Plenary Session of the 18th Central Committee in the groundwater funnel area, the northeast cold area, the heavy metal pollution area, and the ecologically fragile area. The project aims to rehabilitate land, especially cultivated land [3-5], to ensure its sustainable use.

Land fallow is an effective measure widely adopted in developed countries to protect cultivated land, repair the ecological environment, and adjust the planting structure. Implementing a farmland 
fallow system is significant for ensuring food security and sustainable use of resources. The land fallow in developed countries was mostly aimed at regulating grain production, and then gradually evolved into an important means to mitigate overproduction and improve the agricultural environment [6-9]. Europe, the United States, and Japan have been implementing cultivated land fallow since the 1930s, and relatively mature arable land fallow systems have been established [10-12], such as the Conservation Reserve Program (CRP), which was implemented in 1985 by the United States Department of Agriculture [13-15]. Since the implementation of the CRP, the EU has also begun to implement a land preservation plan. In 1988, the European Union launched a five-year voluntary fallow project. Unlike the United States, the EU proposed fallows to control budgets and reduce food production [16-19]. At the same time, many European and American scholars have achieved rich results regarding the response of farmland households to land fallow [20-24], the ecological and environmental effects of land fallow implementation [23,25-28], and the economic effects of land fallow policy implementation [23,29].

While China's research on fallow began relatively late, Chinese scholars have conducted research on the experience of international fallow policy [30-32], the model of land fallow, and the behavior of fallow farmers. These studies mainly focus on empirically studying factors affecting farmers' behavioral decision-making, fallow compensation standards, and fallow implementation methods. For example, in studying the farmer's willingness to participate in fallow, Rao (2016), Li et al. (2015), Yu et al. (2017), Li et al. (2018), and Xie et al. (2018) analyzed the factors affecting farmers' willingness to fallow from the farmers' perspective [32-35]. Chen et al. (2018), Long et al. (2017), Liu et al. (2018), and Xie et al. (2017) [36-39] studied the influential factors and willingness of farmers to participate in fallow in the groundwater funnel area. Yin et al. (2015) studied farmers' willingness to participate in fallow and found great variance in their economic compensation demand as it was significantly affected by their family size, household annual per capita net income, ecological fallow willingness index, and economic compensation expectations [40]. Chen et al. (2018) and Zhang et al. (2019) studied the impact of different compensation models on farmers' welfare from the perspective of farmers' livelihood [36,41,42]. There are also scholars discussing the relationship between farmers' policy response, subsidy methods, and the number of subsidies [43].

In summary, the existing research mainly focuses on the empirical analysis of the internal and external factors affecting farmers' participation in fallow and the validity of fallow compensation. Few scholars have theoretically analyzed the impact of the behavioral strategies of various participants toward the land fallow policy. The cultivated land fallow project is complex and systematic, involving different stakeholders, each with different interests. Among these stakeholders, farmers are the main participants, both as the practitioners and beneficiaries of the fallow project and, thus, the implementation of the fallow project will have a direct impact on the interests of farmers. Whether farmers will participate in fallow is key to successful implementation of the fallow project. As rational brokers, farmers often seek to maximize their own interests when choosing whether to participate in fallow. Therefore, encouraging farmers to participate in fallow is of prime concern to the government.

Land fallow is not only a method to protect cultivated land, but is also an important way to improve the cultivated land productivity. Compensation standard and compensation mode of fallow farmers are important parts of the fallow farmland system [44]. The implementation of fallow will directly reduce farmers' income from farmland and affect farmers' interests. Moreover, land fallow compensation is also directly related to farmers' enthusiasm and willingness to fallow and it is a key issue affecting the effective operation of fallow.

During the implementation of cultivated land fallow in Guizhou, it was seen that, due to the complex implementation environment of fallow and the differences in characteristics and cognitive levels of farmers, most farmers can only make simple decisions instead of maximizing the expected utility. When farmers face multiple choices, farmers' rational thinking ability and behavior choice strategy become imitation behavior or herd behavior in most cases. 
Based on this, this study proposes the following research questions: What are the current problems of farmers participating in fallow in Guizhou Province, and how does one reveal the behavioral choice mechanism of farmers in Guizhou Province participating in fallow project combine the game theory?

Studying the cultivated land fallow project from the perspective of farmers and fully considering their choices has important theoretical and practical significance for promoting the improved implementation of China's fallow policy. This paper, which analyzes farmers' fallow strategies from the perspective of farmer group behavior using hawk-dove game theory to analyze the dynamic equilibrium ratio and behavioral mechanism of farmer fallow (mainly fallow) or non-fallow (replanting) in the process of farmland fallow policy, can effectively explain some of the phenomena observed during the implementation of fallow in Guizhou, which is of real value.

\section{Study Area Summary}

Guizhou is located in the watershed of the Pearl River system and the Yangtze River system and belongs to the typical subtropical plateau mountainous area. Guizhou Province is a traditional farming area with high population density. The regional economy is regressive, and the productivity level is low. Guizhou's economy is greatly dependent on the natural environment, and Guizhou has a very serious degree of rocky desertification. By the end of 2018, the resident population of Guizhou Province was 36 million, and the regional GDP (GDP) was 1,480,645 million yuan, ranking 25th among 31 provinces and cities in China; the per capita GDP reached 41,244 yuan [45]. To better understand the socio-economic situation of the study area, Table 1 shows the regional GDP of the five fallow pilot counties of 2017.

Table 1. Research area 2017 GDP.

\begin{tabular}{cccc}
\hline County & $\begin{array}{c}\text { Gross Domestic Product. } \\
\text { (GDP) (100 Million Yuan) }\end{array}$ & $\begin{array}{c}\text { Per Capita GDP } \\
\text { (Yuan) }\end{array}$ & $\begin{array}{c}\text { GDP Ranking in 88 Counties } \\
\text { in Guizhou Province }\end{array}$ \\
\hline Wanshan & 41.93 & 36,209 & 80 \\
Songtao & 114.52 & 23,319 & 39 \\
Qinglong & 65.03 & 26,579 & 64 \\
Liuzhi & 165.30 & 33,043 & 27 \\
\hline
\end{tabular}

Carbonate rock in Guizhou Province is widely distributed, and is the major part of the southwestern karst landform. The area of rocky desertification reached 3.316 million hectares, accounting for $25.6 \%$ of the total area of rocky desertification in China, and the exposed area of karst accounted for $61.92 \%$ of the total area of the province $[46,47]$. Severe rocky desertification in Guizhou Province has caused frequent soil erosion and natural disasters in some regions, which has also aggravated regional poverty.

Due to the fragile ecological environment and human activities in the karst area of Guizhou Province, a highly unstable regional system of human-land relationship has been formed, which is characterized by poor natural resource endowment, lagging economic development, and severe fragmentation of cultivated land [48,49]. Under the contradiction of this special human-land relationship, the cultivated land in the ecologically fragile areas of Guizhou is mostly in a marginal utilization state [50]. Due to the poor natural conditions of marginal cultivated land, it is difficult to improve the state of cultivated land utilization by strengthening farmland input and improving field management. Farming incomes are difficult to raise, and fallow farmers receive subsidies. Therefore, the implementation of fallow project is very necessary.

In 2016, the Chinese government proposed a pilot project for fallow cultivation in the southwest and northwest regions where there is serious ecological degradation. As shown in Figure 1, the pilots were mainly concentrated in the Wanshan Special Zone, Songtao County; Tongren City, Guizhou Province; Liuzhi District, Liupanshui City, Qinglong County, and Qifeng County; they amounted to a total fallow of 2 million $\mathrm{mu}(1 \mathrm{mu}=0.0667$ hectares $(\mathrm{ha}))$ for the first batch of projects. 


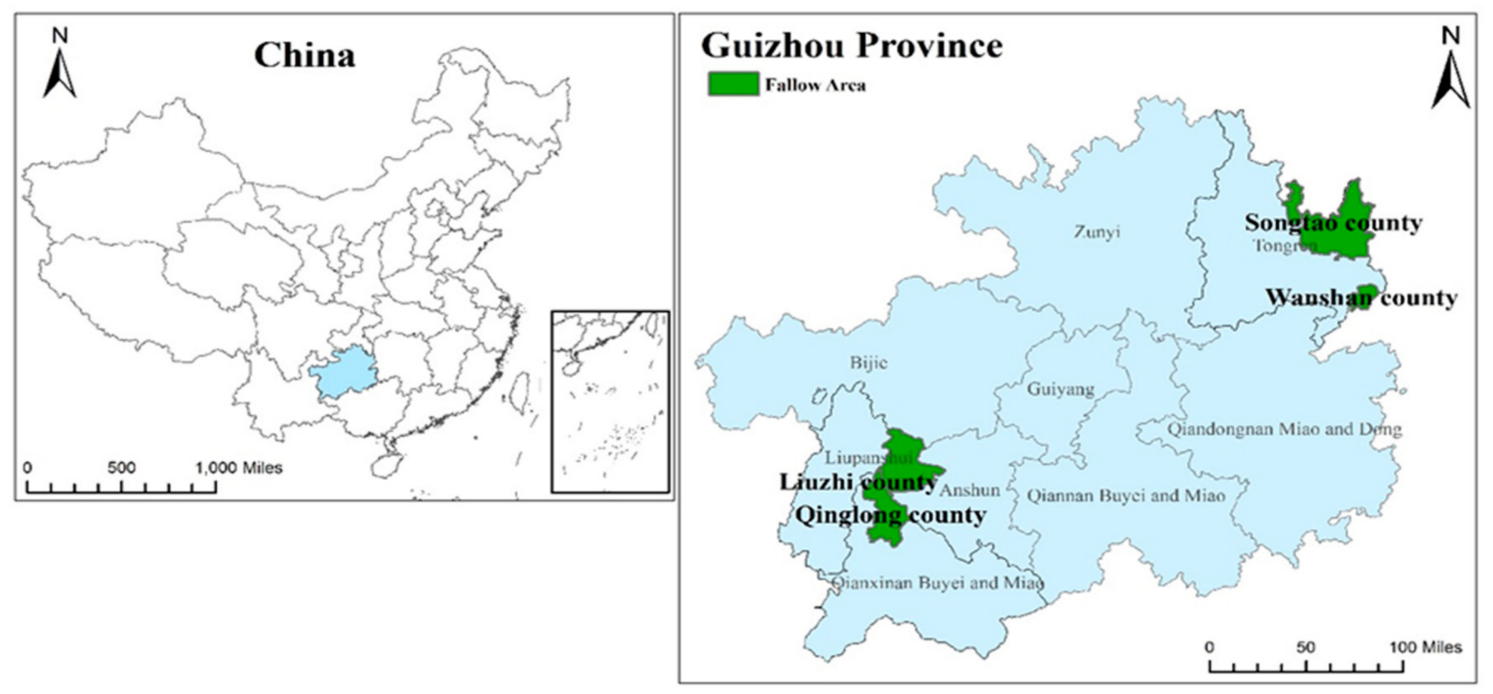

Figure 1. Distribution of cultivated land fallow in Guizhou Province.

\section{Status of the Land Fallow Project in the Study Area}

To further investigate the specific details of the implementation of fallow farmland in Guizhou Province, the research team conducted field research in the Wanshan Special Zone in Songtao County and the Liuzhi Special Zone in Tongren City, Guizhou Province in May and August 2017, respectively. From a total of 700 questionnaires that were sent out, 689 were returned; of these, 46 invalid questionnaires were excluded and 643 valid questionnaires were used. The questionnaire recovery rate was $98.4 \%$, and the questionnaire efficiency was $91.86 \%$.

The basic characteristics of the comprehensive farmers we have learned that the gender of the heads of the survey sample is mostly male, accounting for $86.23 \%$ of the total sample. Most farmers whom engaged in agricultural production are elderly; the education level is concentrated in primary school and below, those with high school and above only account for $5.13 \%$ of the sample size, and the overall education level is low. Among the surveyed households, the family income mainly comes from agriculture, as shown in Table 2.

Table 2. Basic situation of the sample.

\begin{tabular}{ccc}
\hline Farmer Characteristics & Option & Ration (\%) \\
\hline \multirow{2}{*}{ Gender } & Male & 86.23 \\
& Female & 13.37 \\
\hline \multirow{2}{*}{ Age } & $0 \sim 40$ & 9.8 \\
& $41 \sim 60$ & 70.34 \\
Family population & Over 61 years old & 20.86 \\
& $1 \sim 3$ people & 34.37 \\
& $4 \sim 6$ people & 51.79 \\
& More than six people & 13.84 \\
\hline \multirow{2}{*}{ Educational level } & Elementary school and below & 66.10 \\
& Junior high school & 28.15 \\
& High school & 5.13 \\
& College and above & 0.62 \\
\hline \multirow{2}{*}{ Main source of family income } & Agricultural income & 76.36 \\
& Non-agricultural income & 23.64 \\
\hline \multirow{2}{*}{ Whether the farmer is concurrently } & Not concurrently & 61.12 \\
& Concurrently & 38.88 \\
\hline \multirow{2}{*}{ Fon }
\end{tabular}


Through field research, we found that the implementation of the fallow project in Guizhou Province faces many practical problems.

The willingness of the farmers reflects their enthusiasm to participate in the fallow project. It can be seen from Table 3 that most farmers indicated that they are willing to participate in fallow; these farmers accounted for $76.36 \%$ of farmers, while the "unwilling" farmers accounted for $23.63 \%$. It can be seen that the implementation of the cultivated land fallow project in Guizhou Province has a broad public support base.

Table 3. Survey of farmers' participation in cultivated land fallow.

\begin{tabular}{ccccccccc}
\hline Option & $\begin{array}{c}\text { Farmers' } \\
\text { Willingness to } \\
\text { Participate in Fallow }\end{array}$ & \multicolumn{2}{c}{ Farmers' Cognition of the Content of } \\
Fallow Projects & & \multicolumn{2}{c}{$\begin{array}{c}\text { Whether the Farmer is Satisfied } \\
\text { with the Compensation } \\
\text { Amount for the Fallow Project }\end{array}$} \\
\cline { 2 - 9 } & YES & NO & Understanding & General & Do not understand & YES & General & NO \\
\hline Ratio & $76.36 \%$ & $23.63 \%$ & $13.22 \%$ & $25.65 \%$ & $61.13 \%$ & $8.55 \%$ & $41.06 \%$ & $50.39 \%$ \\
\hline
\end{tabular}

To smoothly implementing the arable land fallow project, the main participants must have a full understanding of the project content, including the project's purpose, implementation method, specific requirements, fallow area, fallow period, and so on. Farmers are the most important participant in the implementation of fallow, and their cognition of fallow project is directly related to whether the fallow can achieve the expected results. It can be seen from Table 3 that the farmers do not have sufficient understanding of the fallow project, which is not conducive to the development and implementation of the fallow project.

Through the follow-up cognition and satisfaction survey, we found that although the farmers supported the fallow project, they are still skeptical about cultivated land fallow, as seen from the farmer's cognition of the fallow project implementation and the degree of satisfaction of the subsidy (Table 3). The farmers in the sample area have a low level of awareness of fallow, and most farmers do not fully understand the fallow project, which is not conducive to the further implementation of the fallow project. Additionally, why are some farmers not aware of the cultivated land fallow project but still participate? From the field investigation, these farmers also display a blindly imitative conformity behavior when making decisions about fallow; this behavior is not conducive to successful consolidation of the fallow project.

According to the investigation and analysis results, first, farmers do not know much about fallow policies, but the actual participation is high, which reflects the imitation behavior of some farmers. Secondly, the cultivated land fallow subsidy system in Guizhou Province did not fundamentally encourage farmers to participate in fallow, and most farmers were not satisfied with the implementation of fallow projects. Although farmers are rational brokers, most of them only consider their short-term interests. In the survey area, some farmers resumed plantation on fallow farmland because they did not receive the fallow subsidy in time. Thus, how does one ensure that the farmers do not give up the fallow and resume planting during the fallow period, and will the farmers continue to participate in the fallow after the fallow period? What are the reasons for the change of farmers' strategy? What is the mechanism of farmers' fallow decision-making? These problems deserve much attention.

\section{Hawk-Dove Game Analysis of Farmers' Fallow Behavior}

\subsection{Hawk-Dove Game}

The basic concept of evolutionary game theory is the evolutionary stable strategy (ESS). The intuitive idea is that if the behavior pattern of a group's original group can eliminate any small mutant group, then this behavior pattern must be able to obtain a higher expected payment than the mutant group. As time goes on, the mutant group will eventually disappear from the original group, and the strategy chosen by the original group is the evolutionarily stable strategy [51]. Evolutionary game theory assumes that the game is oft-repeated, and that the players in the game are considered 
to have only bounded rationality. They were randomly selected from a large group and had little or no knowledge of the game they participated in. In evolutionary game theory, participants can obtain decision information directly through their own experience, indirectly by observing other participants' decisions and imitations in a similar environment. Participants can also obtain decision information from the group distribution by observing the history of the game [50-53].

Observing group decision-making helps participants understand what good strategies are. Participants often imitate good strategies, while bad ones are eliminated in the process of evolution. Imitation is an important part of the learning process. Successful behaviors or strategies are not only passed down in the form of preaching but also easily imitated.

In the process of land fallow, due to the complex environment, farmers' own quality and cognitive level are different; most farmers can only adopt simple decision-making strategies instead of maximizing expected utility. As rational brokers, farmers pay more attention to immediate economic interests in dealing with conflicts between economic and ecological interests and are less willing to bear economic costs for ecological benefits. At the same time, in dealing with the conflicts between immediate and long-term interests, farmers must first satisfy their immediate interests due to long-term uncertainties, and actively strive for long-term interests on this basis. The cultivated land fallow project will change the stable living conditions of the farmers. When farmers face multiple behavioral choices, in most cases, farmers' rational thinking ability and behavior choice strategy are replaced by imitative or herd behavior. For the game participants with bounded rationality, whether it is Nash equilibrium or not, the participants with bounded rationality may adopt it. However, farmers do not the transformation to dominant strategy at the same time, but after repeated games of learning and imitating, which belongs to the field of evolutionary game theory.

Therefore, using evolutionary game theory to analyze the farmers' groups participating in fallow is more practical. We use the classic "hawk-Dove" symmetric game model to analyze the dynamic equilibrium ratio of fallow and unfallow, restoration of planting and remain fallow in China.

\subsection{Hypothesis of the Hawk-Dove Game Theory}

In evolutionary game theory, participants can obtain decision information directly through their own experience, or indirectly by observing other participants' decisions and imitation in a similar environment. By observing the distribution of the group, it helps the participants to know what a good strategy is. People often imitate good strategies, while bad strategies are eliminated in the process of evolution. Imitation is an important part of the learning process. Therefore, in order to describe the behavior of participants more accurately, we must examine the dynamic adjustment process of the economic system; the concept of dynamic equilibrium and the dynamic model occupy a very important position in the evolutionary game theory. Thus, we make the following assumptions:

Hypothesis 1. The hawk-dove game theory assumes that the players in the game model include farmer 1 and farmer 2, and each farmer has two strategies: "fallow" and "unfallow (or resume planting)". Since practicing fallow is a voluntary act, regardless of whether farmers are large- or small-scale, they can adopt either strategy.

Hypothesis 2. According to the game model and the reality of fallow in China, the bounded rationality hypothesis assumes that both Farmer 1 and Farmer 2 are "incompletely rational". During the game, either farmer does not adopt a completely rational equilibrium strategy but continues to achieve a stable equilibrium result through continuous learning. This stable equilibrium does not mean that the gamer's strategy is unchanged but that the proportion of the game adopting a certain strategy does not change.

Hypothesis 3. The income hypothesis assumes that when farmers participate in fallow, they will receive the fallow subsidy, the income of the labor transfer after the farmer's fallow and the expected ecological benefit $R$. During the fallow period and due to the unstable nature of the group, the farmer will be able to unfallow (or 
resume planting) to generate the planting income E. In addition, the expected total return of unfallow will be the expected total loss of participation in fallow; it is assumed that if fallow is a rational behavior choice, then $R \geq E$.

\subsection{Research Methods}

Suppose $x$ represents the proportion of farmers who choose fallow and $1-x$ represents the proportion of farmers who choose unfallow. Based on the above assumptions, the game income matrix between farmers is constructed, as shown in Table 4.

Table 4. Revenue matrix between farmers.

\begin{tabular}{lccc}
\hline & \multicolumn{2}{c}{ Farmer 2 } \\
\cline { 3 - 4 } & & FALLOW $(x)$ & UNFALLOW (1-x) \\
\hline \multirow{2}{*}{ Farmer 1 } & FALLOW $(x)$ & $\left(\frac{R}{2}, \frac{R}{2}\right)$ & $(R, E)$ \\
& UNFALLOW $(1-x)$ & $(E, R)$ & $\left(\frac{E}{2}, \frac{E}{2}\right)$ \\
\hline
\end{tabular}

According to the above game income matrix, when the farmer chooses fallow, the return is $R$. If both parties have the same strategy, then the probability of both sides' gains and losses is $\frac{1}{2}$. Therefore, if the farmer chooses to unfallow, then the income of the fallow farmer is $R$ whereas the income of the unfallow farmer is $E$; if both farmers choose to unfallow, their income is each $\frac{E}{2}$.

Bounded rational players may or may not adopt the Nash equilibrium. Therefore, the transformation of both farmers' dominant strategy (rational investment strategy) is not realized simultaneously, but by repeated games of learning and imitation; this belongs to the field of evolutionary game theory.

\subsection{Game Model Solving}

The revenue matrix between the farmers in Table 3 can be used to obtain the expected benefits when farmers choose the "fallow" and "unfallow" strategies:

$$
\begin{aligned}
& u_{1}=x\left(\frac{R}{2}\right)+(1-x)(R)=R\left(1-\frac{x}{2}\right) \\
& u_{2}=x(E)+(1-x)\left(\frac{E}{2}\right)=\frac{E}{2}(x+1)
\end{aligned}
$$

From this, the average expected income of the farmer group can be derived:

$$
\bar{u}=x u_{1}+(1-x) u_{2}=R x+\frac{E}{2}-\frac{(R+E)}{2} x^{2}
$$

According to the dynamic idea of bio replication, when one side of the game adopts a strategy with low returns, it will change its strategy and turn to the other side. Therefore, the proportion of members who adopt the unfallow strategy will change. The rate of change in the fallow strategy is proportional to the above two strategies (fallowing or continuous cultivation) and the extent to which the benefits exceed the average return. The rate of change of $x$, the proportion of the game party adopting the fallow behavior strategy in the above game model, can be expressed by a differential equation known as a "replication equation". The replication equation can generally be abbreviated as $F(x)=\frac{d_{x}}{d_{t}}$. According to this equation, dynamic differential equations can be used to obtain the replication dynamic equation of the game model:

$$
F(x)=\frac{d_{x}}{d_{t}}=x(1-x)\left(u_{1}-u_{2}\right)=x(1-x)\left[\left(R-\frac{E}{2}\right)-\frac{1}{2}(R+E) x\right]
$$


Let $F(x)=\frac{d x}{d t}=0$ be used to obtain the stability points of the equation, $x^{*}=0, x^{*}=1$ and $x^{*}=\frac{(d-b)}{(a-b-c+d)}$, that is, the stable levels of the farmer's ratio $x$ adopting the $\left(\frac{R}{2}, \frac{R}{2}\right)$ strategy in the replication dynamic process.

It is worth noting that in the game process, the replication dynamic equation will still return to the stable state when the decision deviates from the stable point due to the incorrect judgment of the player. This phenomenon requires that when the $x$ direction deviates from the level below the stable point $x^{*}, F(x)>0$; when the $x$ direction deviates from the level above the stable point $x^{*}, F(x)<0$, that is, the derivative of the $F(x)$ at the stable point $F\left(x^{*}\right)$ is less than zero.

When $x^{*}=0$ or $x^{*}=1$, there is no difference between the "fallow" or "unfallow" strategy. According to this assumption, in order to confirm whether the third stable point of the equation is an evolutionary stabilization strategy, we make the following further verification; according to the previous assumptions and the specific implementation of cultivated land fallow, farmers will adopt the fallow policy only when the fallow income is slightly greater than or equal to the income of unfallow. Whether $x^{*}=\frac{(d-b)}{(a-b-c+d)}$ is the stable point of the equation needs further confirmation.

According to the above assumptions, farmers will actively participate in fallow when the respective income is greater than the income from their own cultivation. Assuming that the farmer's fallow income is $R=10$, the income of the farmer's own planting is $E=6$ :

$$
\begin{gathered}
x^{*}=\frac{(d-b)}{(a-b-c+d)}=\frac{2 R-E}{R+E} \\
F(x)=\frac{d_{x}}{d_{t}}=x(1-x)\left(u_{1}-u_{2}\right)=x(1-x)\left[\left(R-\frac{E}{2}\right)-\frac{1}{2}(R+E) x\right]
\end{gathered}
$$

The derivation of $F(x)$ is as follows:

$$
F\left(x^{*}\right)=R-\frac{E}{2}-3 R x+3 \frac{R+E}{2} x^{2}
$$

According to the replication dynamic equation, there are three stable solutions: $x^{*}=0, x^{*}=1$ and $x^{*}=\frac{2 R-E}{R+E}$. To verify whether $x^{*}=\frac{2 R-E}{R+E}$ is the stable point of the equation, $\mathrm{R}=10$ and $\mathrm{E}=6$ are inserted into both Equations (5) and (6) and yield $x=1, x^{*}=\frac{7}{8}$. As shown in Figure 2, when the $x$-direction is shifted above the horizontal level of $x^{*}$, the evolutionary stability strategy requires $\frac{d F\left(x^{*}\right)}{d x}<0$. When inserting $R=10, E=6, x *=\frac{7}{8}$ into the equation to obtain $F(x)<0$, it can be seen that $x^{*}=\frac{2 R-E}{R+E}$ meets all the conditions of the evolutionarily stable strategy (ESS).

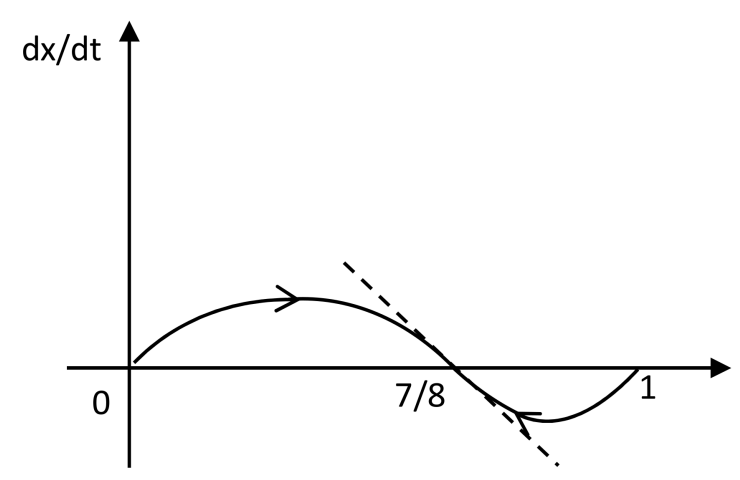

Figure 2. Copying dynamic equation phase diagram of the game model.

\subsection{Result}

According to the above model, the ESS solution of the replicated dynamic equation is $x^{*}=\frac{2 R-E}{R+E}$, that is, the intuitive economic explanation of this evolutionary stability strategy is that the dynamic 
equilibrium ratio of farmers' decision-making behavior by adopting irrational unfallow and rational fallow is $\frac{2 R-E}{R+E}$.

To better understand this decision-making behavior, the following hypothesis will be made based on actual conditions and the results will be verified by using Netlogo evolutionary simulation software (Wilensky, U. (1999). NetLogo. http://ccl.northwestern.edu/netlogo/. Center for Connected Learning and Computer-Based Modeling, Northwestern University, Evanston, IL, USA). This paper is based on the actual situation in Guizhou Province where the fallow subsidy is 600 yuan/mu and makes the following hypotheses:

Hypothesis 4 (H4). Assume that when the farmer's fallow income is 800 yuan per mu, the farmer's planting income is 600 yuan per mu;

Hypothesis 5 (H5). Assume that when the farmer's fallow income is 1000 yuan per mu, the farmer's planting income is 600 yuan per mu;

Hypothesis 6 (H6). Assume that when the farmer's fallow income is 800 yuan per mu, the farmer's planting income is 500 yuan per mu;

Hypothesis 7 (H7). Assume that when the farmer's fallow income is 600 yuan per mu, the farmer's planting income is 600 yuan per mu;

Hypothesis 8 (H8). Assume that when the farmer's fallow income is 600 yuan per mu, the farmer's planting income is 300 yuan per mu;

Hypothesis 9 (H9). Assume that when the farmer's fallow income is 600 yuan per mu, the farmer's planting income is 800 yuan per mu;

Hypothesis 10 (H10). Assume that when the farmer's fallow income is 400 yuan per mu, the farmer's planting income is 800 yuan per $\mathrm{mu}$; and

Hypothesis 11 (H11). Assume that when the farmer's fallow income is 300 yuan per mu, the farmer's planting income is 800 yuan per mu. Table 5:

The dynamic equilibrium ratio of farmer's decision to fallow can be concluded as shown in

Table 5. Dynamic equilibrium ratio of farmer fallow strategy.

\begin{tabular}{lccc}
\hline & Farmer's Fallow Income & Farming Income & ESS \\
\hline H4 & 800 & 600 & $5 / 8$ \\
H5 & 1000 & 600 & $7 / 8$ \\
H6 & 800 & 500 & $11 / 13$ \\
H7 & 600 & 600 & $1 / 2$ \\
H8 & 600 & 300 & 1 \\
H9 & 600 & 800 & $2 / 7$ \\
H10 & 400 & 800 & 0 \\
H11 & 300 & 800 & $-2 / 11$ \\
\hline
\end{tabular}

It can be seen from the above assumptions that when the farmer's total fallow income is greater than the planting income, i.e., assumption 1 that includes hypotheses 5, 6, and 8, the dynamic equilibrium ratio of the farmer's fallow behavior decision is $5 / 8,7 / 8,11 / 13$, respectively. Hypothesis 4 is compared with Hypothesis 5, showing higher fallow yield results in a higher dynamic equilibrium ratio when the planting income is constant. When the fallow yields are the same, that is, comparing 
hypothesis 4 with hypothesis 6 , the dynamic equilibrium ratio of the latter is greater than the former, that is, the lower the planting income, the higher the dynamic equilibrium ratio. From this we can infer that when the planting income is constant, the dynamic equilibrium ratio increases with the increase in fallow yield; when the fallow yield is constant, the dynamic equilibrium ratio decreases with the increase in planting income. In hypothesis 8 , when the fallow income is twice the planting income, the dynamic equilibrium ratio of the farmer's fallow decision is 1 , that is, all farmers make the decision to fallow, as shown in Figure 3.

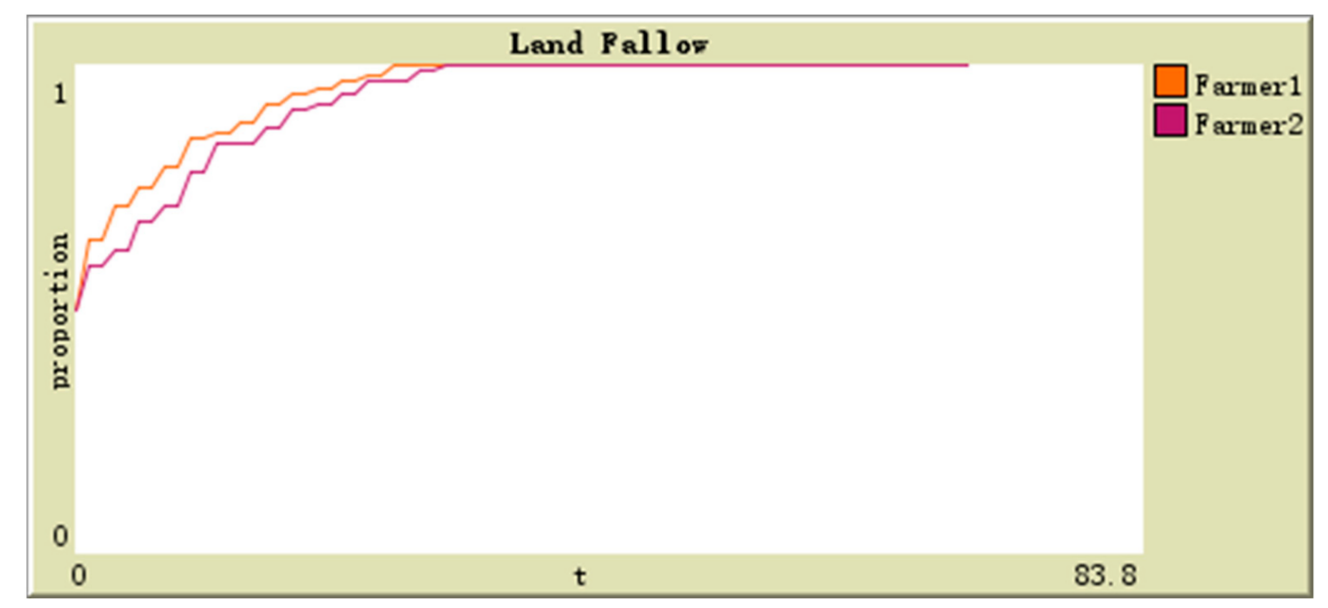

Figure 3. Hypothesis 8 stable point evolution simulation results.

If assuming that the ESS solution of hypothesis 7 is $1 / 2$, that is, the fallow yield is equal to the planting income, half of the farmers will fallow and half will unfallow.

As shown in Figure 4, the farmer's fallow income is less than the planting income in hypotheses 9-11. In hypothesis 9 , when the fallow income is $3 / 4$ of the planting income, $2 / 7$ of the farmers will make the fallow decision, but when the planting income is twice that of the fallow's income, the 0 value of the dynamic equilibrium ratio of the farmer's fallow decision indicates that all farmers will unfallow or resume planting. In hypothesis 11, the planting income is more than twice that of the fallow. At this time, the dynamic equilibrium ratio is negative, indicating that there will be a 2/11 ratio of farmers from the initial fallow to unfallow.

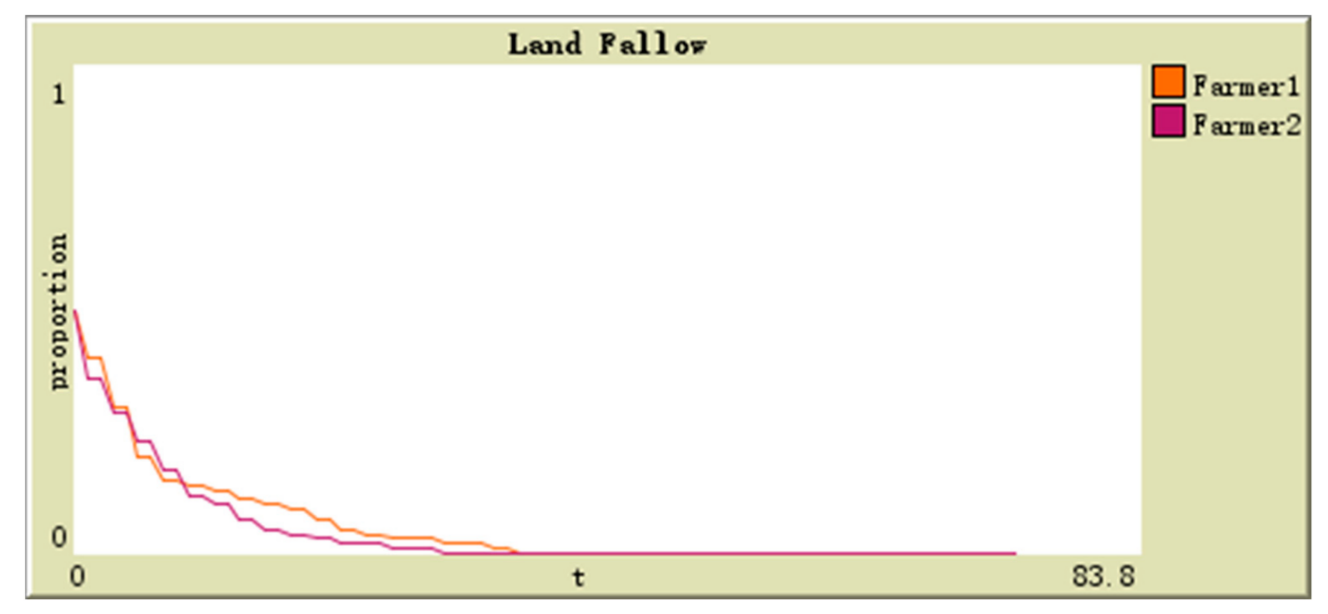

Figure 4. Stable point evolution simulation results. 


\section{Conclusions, Discussion, and Implications}

\subsection{Conclusions}

By constructing the hawk-dove game theory between farmers' groups, we reveal the decision-making mechanism of farmers' participation in cultivated land fallow, powerfully explain some practical problems in the implementation of the fallow project in Guizhou, and draw the following conclusions:

(1) In the case of a single individual, farmers make different behavioral decisions by considering their own interests. However, in the implementation of the fallow project, the farmer is not only an individual, he is in a group. The behavior of the farmer will be affected by other farmers in the same situation, and there is a mutual incentive and imitation effect between the farmer groups. The root cause of the decision-making imitation behavior within this group of farmers still remains their own interests. In the fallow project, the most important driver of interest is fallow compensation, which is consistent with the research results of Xie et al. (2018), Long (2017), and Wang et al. (2018) [37,49,54].

(2) The root cause for the formation of farmers' imitative behavior is driven by economic interests. During the implementation of the fallow project, farmers' own interests drive the farmers in the group, and they will inevitably implement strategies that they believe will benefit maximization by learning and imitating the decisions of other farmers. The stronger the incentives for the economic benefits of the fallow project, the faster the farmers learn and imitate, and the more effective the behavior.

(3) The dynamic equilibrium proportion of "irrational behavior strategy (unfallow)" and "rational behavior strategy (fallow)" adopted by farmers ultimately depends on the benefit ratio of the two behaviors. The greater the proportion of rationality (fallow) used by farmers, the greater the proportion of rational farmers. On the contrary, the proportion of rational farmers is smaller. Additionally, farmers participating in fallow can exert a good demonstration effect.

(4) The greater the proportion of rationality (fallow) used by farmers, the stronger the demonstration effect of rational strategy, and the faster the irrational strategy (unfallow) will be transformed into rational strategy. When the difference between the expected return of the rational strategy and the average expected return is greater, the more irrational strategy can be transformed into the rational strategy. If higher income generated from fallow farming produces a demonstration effect by peasant households participating in fallow, there will be rapid adoption of fallow; fewer farmers will adopt the strategy of unfallow, thus allowing for results of fallow can be successfully consolidated.

\subsection{Discussion}

Through the game model analysis, we conclude that when the farmer's fallow income is twice the planting income, successful results of group fallow will be realized. In contrast, when the farmer's planting income is more than twice the income of fallow, farmers previously practicing fallow will resume planting.

Based on the data from field research, we found that the average planting income of farmers in Guizhou is 728.18 yuan, which is higher than the fallow compensation. This finding is not conducive to the successful consolidation of the fallow project, which explains why farmers in some fallow areas have participated in fallow cultivation and then resumed planting. Considering that farmers in fallow areas vary in age, education level, and other internal or external factors, such as socioeconomic factors, it is uncertain whether farmers can obtain benefits other than fallow subsidies. The uncertainty of the income earned by the fallow farmer as a rational, small farmers will also hinder farmers from participating in and maintaining the decision of fallow.

It can be seen from the above analysis that if the farmer group participates in the fallow, the government department is required to ensure that they can obtain a certain level of stable income after fallow. This phenomenon explains why the farmers in the fallow area of Guizhou Province have resumed planting after participating in the fallow. Since the income from farmers' cultivation will constantly vacillate due to factors such as food prices, a flexible and dynamic subsidy policy should be 
implemented when formulating compensation standards. Farmers will likewise be motivated if they are given sufficient economic benefits.

\subsection{Implications}

Based on the above conclusions and discussion, we have formulated the following targeted policy recommendations as follows:

First, when implementing a fallow policy, the government should follow the principle of volunteerism and respect farmers' choices, and farmers should be given more voluntary choices. Then, government should give farmers who are willing to follow full and continuous fallow incentives, ensure the enthusiasm of farmers to fallow, improve the implementation efficiency of fallow projects, and effectively avoid the phenomenon of deforestation. If the government gives sufficient incentives to the fallow farmers, their enthusiasm will be greatly mobilized, the implementation of the fallow project will be effectively stimulated, and the eco-environment objectives expected by the policy makers will be easier to achieve.

Second, a well-designed subsidy standard can balance the private and social benefits of fallow and the government should protect the expected or actual fallow income of farmers as much as possible, increase the subsidy income of farmers participating in fallow, and improve the level of rural outdoor business after fallow. Since the income of farmers participating in fallow vacillates over time, the government should implement an elastic subsidy policy to stimulate farmers' economic interests to encourage the adoption or maintenance of fallow strategies.

Third, local governments need to actively cultivate new industries, promote industrial transformation, and increase employment. Local governments must develop rural secondary and tertiary industries, increase employment opportunities, and encourage farmers to work beyond the farm. The government can also guide farmers to actively and orderly transfer land and promote large-scale agricultural operations. In implementing the arable land fallow project, the local government should combine the cultivated land fallow with local economic development, create more opportunities, guarantee the basic livelihood of the farmers, and improve farmers' quality of life in order to ensure the stability and continuity of the project.

Finally, the government should introduce modern fallow management, monitoring, and evaluation systems. China's fallow project is continually expanding. The relevant departments should formulate and promulgate detailed follow-up implementation policies as soon as possible, strengthen the propaganda of the projects, improve policy transparency, and improve farmers' understanding and awareness of the projects to avoid failure. At the same time, the central government should formulate a sound dynamic supervision mechanism to assess local governments and supervise the projects by introducing third-party supervision agencies to successfully consolidate the results and ultimately achieve the sustainability and effectiveness of fallow.

In addition, this paper mainly analyzes the changes in farmers' decision-making behavior during the implementation of the fallow project from the sole perspective of farmers' groups and does not consider other groups, such as the central government, local governments, or third-party managers, and the behavioral decisions of these stakeholders on the implementation of fallow projects. These stakeholders will have different influences, which is worthy of subsequent research.

Author Contributions: W.Q. was responsible for data collecting and carried out the analyses. All the authors drafted the manuscript, and approved the final manuscript.

Funding: This study was supported by the National Natural Science Foundation of China (No. 41561040 and No. 71803071); the Academic and Technical Leaders Funding Program for Major Disciplines in Jiangxi Province (No. 20172BCB22011); the Technology Foundation of Jiangxi Education Department of China (No. KJLD14033 and No. GJJ160431); and the Fok Ying-Tung Fund (No. 141084).

Conflicts of Interest: The authors declare no conflict of interest. 


\section{References}

1. Liu, J.; Zhang, Z.; Xu, X.; Kuang, W.; Zhou, W.; Zhang, S.; Li, R.; Yan, C.; Yu, S.; Jiang, N. Spatial Patterns and Driving Forces of Land Use Change in China in the Early 21st Century. Acta Geogr. Sin. 2009, 64, 1411-1420. [CrossRef]

2. Jin, T. Effects of Cultivated Land Use on Temporal-Spatial Variation of Grain Production in China. J. Nat. Resour. 2014, 29, 911-919.

3. Shen, X.Q.; Wu, C.F. Neo-liberal agri-environment policy: Modes and implications. China Land Sci. 2016, 1, 68-74.

4. Tan, Y.Z.; Wu, C.F.; Wang, Q.; Zhou, L.Q.; Yan, D. The Change of Cultivated Land and Ecological Environment Effects Driven by the Policy of Dynamic Equilibrium of the Total Cultivated Land. J. Nat. Resour. 2005, 5, 727-734.

5. Yu, Z.N.; Wu, C.F.; Shen, X.Q. Study of Farmers' Willingness for Land Fallow Based on IAD Extension Decision Model. J. Nat. Resour. 2017, 32, 198-209.

6. Chen, Z.T.; Yang, Q.Y. Fundamental framework of China's fallow system. China Popul. Resour. Environ. 2017, 27, 126-136.

7. Sobrinho, M.S.; Tabarelli, M.; Machado, I.C. Land use, fallow period and the recovery of a Caatinga forest. Biotropica 2016, 48, 586-597. [CrossRef]

8. Pi, H.; Sharratt, B.; Schillinger, W.F.; Bary, A.I.; Cogger, C.G. Wind erosion potential of a winter wheat-summer fallow rotation after land application of biosolids. Aeolian Res. 2018, 32, 53-59. [CrossRef]

9. Santín-Montanyá, M.I.; Casanova, C.; Zambrana, E.; Sánchez, F.J.; Tenorio, J.L. Arable weed species associated with soil tillage systems under mediterranean conditions. Land Degrad. Dev. 2018, 29, 865-874. [CrossRef]

10. Luo, B. Experience and reference from foreign food safety management. Economist 2012, 9, 97-102. (In Chinese)

11. Zhao, Q.G.; Teng, Y.; Huang, G.Q. Consideration about exploring pilot program of farmland rotation and fallow system in china. Ecol. Environ. Sci. 2017, 26, 1-5. (In Chinese)

12. Xiang, Q.; Yin, R.A. The practice and experience of the US environmental fallow plan. For. Econ. 2006, 73-78. (In Chinese) [CrossRef]

13. Zhu, W.Q. The analysis of Conservation Reserve Program of the United States of America. For. Econ. 2009, 12, 122-128. (In Chinese) [CrossRef]

14. Zhu, W.Q. The analysis of Conservation Reserve Program of the United States of America. For. Econ. 2010, 1, 123-128. (In Chinese) [CrossRef]

15. Kirwan, B.; Lubowski, R.N.; Roberts, M.J. How Cost-Effective Are Land Retirement Auctions? Estimating the Difference between Payments and Willingness to Accept in the Conservation Reserve Program. Am. J. Agric. Econ. 2005, 87, 1239-1247. [CrossRef]

16. Stubbs, M. Conservation Reserve Program (CRP): Status and Issues; Library of Congress, Congressional Research Service: Washington, DC, USA, 2014.

17. Jones, A. The impact of the EC's set-aside program: The response of farm businesses in Rendsburg-Eckernförde, Germany. Land Use Policy 1991, 8, 108-124. [CrossRef]

18. Siebert, R.; Berger, G.; Lorenz, J. Assessing German farmers' attitudes regarding nature conservation set-aside in regions dominated by arable farming. J. Nat. Conserv. 2010, 18, 327-337. [CrossRef]

19. Baylis, K.; Peplow, S.; Rausser, G. Agri-environmental policies in the EU and United States: A comparison. Ecol. Econ. 2008, 65, 753-764. [CrossRef]

20. Reimer, A.P.; Gramig, B.M.; Prokopy, L.S. Farmers and conservation programs: Explaining differences in Environmental Quality Incentives Program applications between states. J. Soil Water Conserv. 2013, 68, 110-119. [CrossRef]

21. Lohr, L.; Park, T.A. Utility-Consistent Discrete-Continuous Choices in Soil Conservation. Land Econ. 1995, 71, 474-490. [CrossRef]

22. Ho, P.P.S. Book review of Selling Forest Environmental Services: Market-based Mechanisms for Conservation and Development. Aust. J. Agric. Resour. Econ. 2004, 48, 557-560.

23. Fraser, I. Agricultural Land Retirement and Slippage: Lessons from an Australian Case Study. Land Econ. 2005, 81, 206-226. [CrossRef]

24. Ibendahl, G. Risk-Adjusted Comparison of Conservation Reserve Program Payments Versus Production Payments for a Corn-Soybean Farmer. J. Agric. Appl. Econ. 2004, 36, 425-434. [CrossRef] 
25. Gumma, M.K.; Thenkabail, P.S.; Teluguntla, P. Mapping rice-fallow cropland areas for short-season grain legumes intensification in South Asia using MODIS 250m time-series data. Int. J. Digit. Earth 2016, 9, 981-1003. [CrossRef]

26. Krishna, G.M.; Thenkabail, P.S.; Charyulu, D.K. Mapping cropland fallow areas in myanmar to scale up sustainable intensification of pulse crops in the farming system. GISci. Remote Sens. 2018, 55, 926-949.

27. Wu, J.J. Slippage Effects of the Conservation Reserve Program: Reply. Am. J. Agric. Econ. 2005, 87, 251-254. [CrossRef]

28. Luo, B.; Li, J.B.; Huang, G.H. A simulation-based interval two-stage stochastic model for agricultural non-point source pollution control through land retirement. Sci. Total Environ. 2006, 361, 38-56. [CrossRef] [PubMed]

29. Fraser, I.; Hone, P. Agricultural land retirement: Lessons from an Australian case study. Land Use Policy 2001, 20, 61-72. [CrossRef]

30. Wang, X.; Li, X.B.; Xin, L.J. Ecological compensation for winter wheat abandonment in groundwater over-exploited areas in the North China Plain. Acta Geogr. Sin. 2016, 71, 829-839. (In Chinese) [CrossRef]

31. Zhang, Y.H. Analysis of American Agricultural Resources and Environmental Protection Projects and Its Enlightenment. Chin. Rural Econ. 2010, 1, 83-91. (In Chinese)

32. Rao, J. Summary of developed countries' farmland rest "and the enlightenment to China. J. Agrotech. Econ. 2016, 9, 118-128. (In Chinese)

33. Li, Z.; Yang, J. Fallow willingness of rural households in Poyang Lake main grain-producing areas and its influencing factors. Guangdong Agric. Sci. 2015, 22, 162-167. (In Chinese)

34. Li, Z.; Yang, Q.Y.; Liao, J.R. Fallow compensation based on farmer willingness to accept in Hebei. Resour. Sci. 2018, 40, 1375-1386. (In Chinese)

35. Xie, H.L.; Wang, W.; Zhang, X.M. Evolutionary game and simulation of management strategies of fallow cultivated land: A case study in Hunan province, China. Land Use Policy 2018, 71, 86-97. [CrossRef]

36. Chen, Y.D.; Yang, Q.Y.; Zeng, L.; Yang, R.H.; Liu, S.H. Study on the demand for differentiated compensation of fallow farmers in different livelihood conditions-A case study in xingtai, hebei province. Chin. J. Agric. Resour. Reg. Plan. 2018, 39, 196-203, 223. (In Chinese)

37. Long, Y.Q.; Wang, C.; Deng, C. Fallow willingness of farmland of different types of peasant households and influencing factors in the groundwater funnel area in Xingtai City. Resour. Sci. 2017, 39, 1834-1843.

38. Liu, D.; Hu, Z.T.; Jin, L.S. Satisfaction of rural households on the fallow program and its influencing factors in groundwater over-exploited areas in North China Plain. J. Arid Land Resour. Environ. 2018, 32, $22-27$. (In Chinese)

39. Xie, H.L.; Chen, L.J. Influence Factors and Ecological Compensation Standard of Winter Wheat-fallow in the Groundwater Funnel Area. J. Nat. Resour. 2017, 32, 2012-2022.

40. Yin, K.; Xiao, Y. Empirical research on household willingness and its caused factors for economic compensation of eco-fallow in the water-level fluctuation zone of the Three Gorges reservoir area. Sci. Geogr. Sin. 2015, 35, 1123-1129. (In Chinese)

41. Zhang, J.Y.; Yang, Q.Y.; Bi, G.H. Research on fallow compensation model from the perspective of rural households' livelihood. J. Arid Land Resour. Environ. 2019, 33, 25-30. (In Chinese)

42. Zhang, J.Y.; Yang, Q.Y. Study on the Changes of Fallow Farmers' Welfare in Different Livelihood Assets Allocation: Empirical Analysis of Yunnan Fallow Pilot Area. China Land Sci. 2019, 33, 25-32. (In Chinese)

43. Tan, Y.; Zhao, Y.; Yu, Z. Subsidy policies on fallow of cultivated land in selected countries and regions and their enlightenment to China. Nongye Gongcheng Xuebao Trans. Chin. Soc. Agric. Eng. 2017, 33, 249-257.

44. Xie, S.Y. How to achieve stable matching in two-way selection. Science 2013, 65, 57-59. (In Chinese)

45. Guizhou Provincial Bureau of Statistics National Bureau of Statistics Guizhou Survey Corps. Guizhou Provincial Statistical Report on National Economic and Social Development 2018. (In Chinese)

46. Yang, Q.Y.; Zeng, L.; Liao, J.R.; Yang, R.H.; Chen, Y.D. Performance Evaluation of Compensation in the Pilot Phase of Fallow System Performance Evaluation of Compensation in the Pilot Phase of Fallow System. Econ. Geogr. 2018, 38, 143-152.

47. Li, Y.B.; Tan, Q.; Wang, S.J. Current status, problems analysis and basic framework of karst rocky desertification research. Sci. Soil Water Conserv. 2005, 3, 27-34. (In Chinese)

48. An, Y.L. A tentative study on structure and function of man-land relationship areal system in karst terrains. Carsologica Sin. 1994, 13, 153-159. 
49. Wang, L.W. Research on the land sustainable use in the north vulnerable areas of China. Chin. Rural Econ. 2003, 12, 58-63. (In Chinese)

50. Zhang, L.Q.; Feng, C.W. Rationality and Bounded Rationality: On the Relationship between Classical Game Theory and Evolutionary Game Theory. J. World Econ. 2001, 8, 74-78. (In Chinese)

51. Xie, S.Y. Evolutionary Game Theory under the Condition of Bounded Rationality. J. Shanghai Univ. Financ. Econ. 2001, 5, 3-9. (In Chinese)

52. Ke, S.F. Analysis of farmer households' returning farmland based on the perspective of evolutionary game theory. For. Econ. 2007, 2, 59-62. (In Chinese)

53. Zhang, J.H.; Gao, H.; Yuan, O.Y.; Zhang, J.L. Evaluation of Soil Erosion Sensitivity in Qianxi County, Guizhou Province. China Soil Water Conserv. Sci. 2018, 16, 88-94. (In Chinese)

54. Xie, H.L.; Cheng, L.J.; Lu, H. Farmers' responses to the winter wheat fallow policy in the groundwater funnel area of China. Land Use Policy 2018, 73, 195-204. [CrossRef]

(C) 2019 by the authors. Licensee MDPI, Basel, Switzerland. This article is an open access article distributed under the terms and conditions of the Creative Commons Attribution (CC BY) license (http://creativecommons.org/licenses/by/4.0/). 